\title{
O RELÓGIO URBANO: A VIDA REGRADA PELO TEMPO DA FÁBRICA
}

\author{
Greyci Backes Bolzan, autora
}

greycibbolzan@gmail.com

Larissa Mörschbächer, coautora

larissa.morschbacher@hotmail.com

Ana Lúcia Costa de Oliveira, coautora

lucostoli@gmail.com

Aline Montagna da Silveira, orientadora

alinemontagna@yahoo.com.br

\section{RESUMO}

O trabalho propõe uma discussão sobre as utopias do final do século XIX e início do século XX (BENEVOLO 1989, 2001; CHOAY, 2002), buscando compreender, dentro das propostas do urbanismo progressista, ideias que possam ter repercutido no sul do Rio Grande do Sul. Nessa perspectiva, debruça-se sobre as vilas operárias e equipamentos urbanos construídos no Complexo Rheingantz, na cidade de Rio Grande. A implantação tipológica do conjunto arquitetônico e a linguagem das vilas operárias permitem ler, no conjunto edificado, a estratificação social da fábrica, o caráter assistencialista dos equipamentos propostos (escola, jardim de infância, armazém e enfermaria) e os mecanismos implícitos de dominação e controle, entre eles a presença do relógio urbano, regrando a vida pelo tempo da fábrica. A integridade do conjunto e a sua importância justificaram o tombamento do Complexo Rheingantz pelo Instituto do Patrimônio Histórico e Artístico do Estado do Rio Grande do Sul (IPHAE) em 2013.

Palavras-chave: Arquitetura e Urbanismo; Patrimônio Cultural; Rio Grande; Vilas Operárias; Complexo Rheingantz.

\section{INTRODUÇÃO}

O final do século XVIII foi marcado pela Revolução Industrial, considerada um dos maiores processos de mudanças econômicas e sociais da humanidade. O desenvolvimento tecnológico têxtil modificou os processos produtivos e o ritmo de vida 
das famílias, fazendo com que a produção, antes difusa por todo território, fosse substituída pelo trabalho concentrado nas grandes fábricas. Desta forma, camponeses e artesãos foram transformados em proletários assalariados, intensificando o êxodo da população rural, situação agravada pelos avanços tecnológicos da produção agrícola que ocorreram paralelamente ao desenvolvimento dos modos de produção industrial. Esse momento de transição foi marcado pelo ritmo acelerado de urbanização dos grandes centros, expandindo essas áreas sem um planejamento prévio (CALABI, 2012).

A corrente do urbanismo progressista teve como principal enfoque a crítica ao panorama social pós Revolução Industrial, em especial ao surgimento de grandes centros urbanos, com déficit habitacional e condições de vida insalubres para a classe operária. Nessa perspectiva, foram estudadas as propostas das comunidades cooperativas de Owen, do Falanstério (de Charles Fourier) e do Familistério (de Godin) (BENEVOLO 1989, 2001; CALABI, 2012; CHOAY, 2002).

O presente trabalho teve como objetivo analisar as repercussões que a corrente progressista do urbanismo europeu teve no planejamento e na construção do Complexo Rheingantz. Os procedimentos metodológicos utilizados nesta análise foram $o$ levantamento urbano e arquitetônico do sítio histórico, a coleta de dados em documentos históricos e a revisão bibliográfica em livros, artigos e dissertações sobre o tema. A partir do referencial teórico, este ensaio buscou analisar as edificações que formam o Complexo Rheingantz (localizadas dentro da poligonal de tombamento do IPHAE), com o intuito de compreender a organização social e espacial estabelecida pela empresa e as estratégias de dominação e controle de seus operários que se materializam no ambiente edificado.

\section{AS UTOPIAS DO SÉCULO XIX E XX}

A Revolução Industrial é um grande marco na história da humanidade. Representou não apenas a inovação tecnológica e de maquinário, mas também um cenário de intensas mudanças na paisagem urbana. Estas transformações, decorrentes do crescimento desenfreado da população em determinadas cidades, não foram acompanhadas por uma infraestrutura urbana adequada.

A indústria têxtil, a máquina a vapor e a estrada de ferro estão fortemente relacionadas a este processo que resultou na produção e no consumo em massa. Assim, a fábrica passou a ser um importante protagonista dentro dos aglomerados urbanos. As 
cidades localizadas mais estrategicamente, ou que se industrializaram mais cedo, logo tiveram como retorno o seu crescimento (GUIMARÃES, 2004) e foram justamente nestas que os problemas decorrentes do aumento populacional se tornaram evidentes em questões como saneamento básico, déficit habitacional e tráfego.

No final do século XIX começam a surgir análises e discussões com a finalidade de compreender e organizar este novo panorama urbano que estava se formando. François Choay divide essas posturas em três grupos, de acordo com suas intenções teóricas: Urbanistas Progressistas, Culturalistas e Naturalistas. Dentre estas três correntes, a que possui maior relevância para a compreensão da proposta do presente trabalho é o urbanismo progressista.

A corrente progressista de pensamento revela suas crítica ao panorama social dos grandes centros urbanos, caracterizados pelo déficit habitacional e pelas péssimas condições de vida para a classe operária. De acordo com Choay, a ideia central e comum aos autores que compartilham dessa perspectiva é a concepção de homem e da razão, na qual o homem e suas necessidades são entendidos como "tipo". Parte-se do pressuposto que os indivíduos podem ser padronizados, ou seja, que a racionalização do ser e da ciência possibilita solucionar os problemas do indivíduo e da sociedade. A ideia de progresso também direciona o pensamento dos autores para o futuro. Este futuro, todavia, é pensado a partir de regras que se estendem para além da fábrica.

Os modelos propõem uma localização "fragmentada e atomizada" (CHOAY, 1979) através da idealização de modelos-tipos de cidades-campo, ou seja, projetos de cidades opostos à concentração populacional da época e que poderiam ser aplicados em diferentes locais. Robert Owen (1771-1858), proprietário de uma tecelagem de algodão, destaca-se por ser vanguarda em iniciativas filantrópicas e propor melhorias para a classe trabalhadora. Seu plano visa uma comunidade cooperativa autossustentável, que combina indústria e agronomia. Ele também discute problemas organizativos espaciais para os quais propõe um esquema-modelo (Figura 1) como solução. 


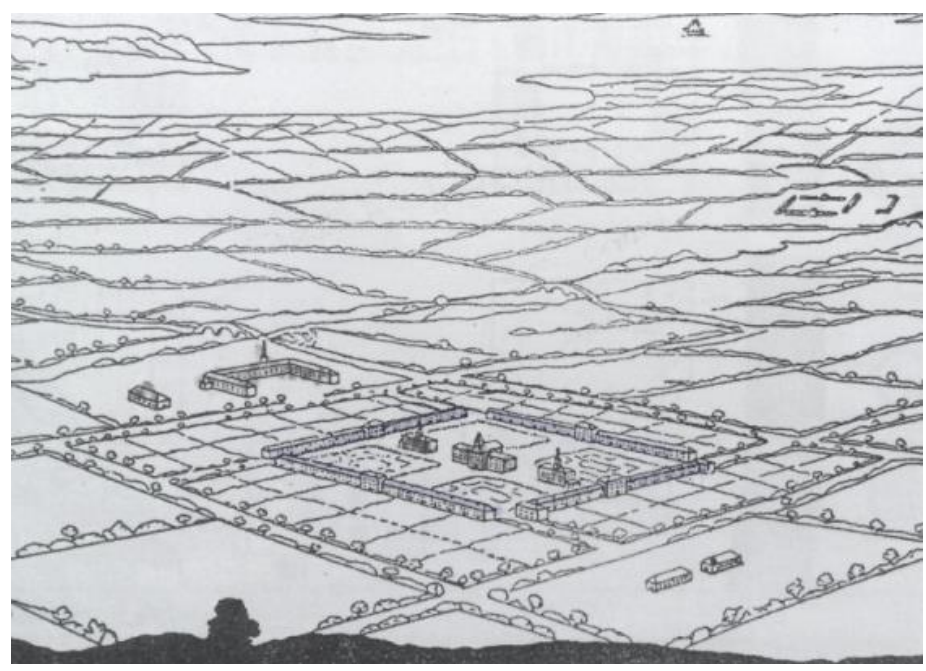

Figura 1: Desenho esquemático da comunidade cooperativa de Owen. Fonte: GUIMARÃES, P. Paulino. Configuração Urbana: Evolução, Avaliação, Planejamento e Urbanização. São Paulo: Prolivros, 2004. p. 73.

Nesse sentido, uma lógica de paternalismo social foi o que norteou o surgimento das primeiras vilas operárias. Estas, compostas por um conjunto de habitações e serviços comunitários, localizavam-se nas proximidades da fábrica, fator que possibilitava o controle sobre os possíveis conflitos gerados pela nova forma de organização urbana. $\mathrm{Na}$ Bélgica, um exemplar desta realidade foi o conjunto elíptico Grand Hornu. O projeto do arquiteto Bruno Renard centralizou as oficinas e a sede administrativa no terreno, dispondo de forma trapezoidal o conjunto de moradias e mobiliários urbano. Como marco simbólico um relógio é apoiado no pedestal em cima do edifício do escritório da fábrica, demarcando não apenas a fusão entre as tipologias arquitetônicas e as fusões de produção industrial, como também a vida, sendo esta regrada pelo tempo da fábrica (CALABI, 2012).

Charles Fourier (1771-1837), outro representante da corrente progressista, condenava uma sociedade baseada em interesses individuais e pregava a harmonia universal. Ele compreendia a evolução da sociedade por meio da superação de períodos históricos que culminariam em uma sociedade regida pela ordem. Nessa perspectiva, a sociedade da época estava em transição de um período de Barbárie para um período de Civilização (BENEVOLO, 1994). Por meio deste conceito, Fourier desenvolveu um projeto denominado Phalastére: um modelo de cidade que comportaria 2.000 pessoas, que seriam alojadas em apartamentos individuais, com áreas sociais e equipamentos compartilhados - tais como biblioteca, sala do conselho, cozinha, sala de refeições, 
lavanderia, sala de banho, dentre outras.

Jean Baptiste Godin (1817-1889) propõe uma redução do modelo de Fourier, denominada Familistério (BENEVOLO, 1994). Para Godin, a experiência seria apenas de caráter industrial e o lucro obtido não deveria ser dividido igualitariamente. Outra mudança em relação à proposta de Fourier dizia respeito às moradias: cada família teria seu alojamento privado, com exceção de alguns equipamentos de interesse comum. Segundo Benevolo, o Familistério de Godin foi considerado a experiência mais bem sucedida dentre as testadas no século XIX pelos teóricos do socialismo, apesar de também ser criticada por Marx e Engels.

Contudo, apesar dos ideais progressistas terem por objetivo "libertar a existência cotidiana de uma parte das taras e servidões da grande cidade industrial", estes geraram sistemas limitadores e repressivos (CHOAY, 1979, p. 10). O funcionário estaria limitado na relação com o espaço em que habitava, visto que este estaria preestabelecido pelo modelo imposto. Ou seja, o trabalhador teria uma casa padronizada sem que fossem consideradas as suas necessidades e ambições particulares em uma determinada localização também preestabelecida - conforme, por exemplo, o proposto nos projetos de Owen e no Phalastére de Fourier.

A outra problemática apontada pela autora diz respeito ao paternalismo político, já que por estarem bastante envolvidos com o seu local trabalho, os funcionários também estarão mais sujeitos a serem manipulados e controlados. Este argumento verifica-se de forma clara na obra de Owen.

\footnotetext{
Qualquer programa para melhorar as condições dos trabalhadores deve compreender meios para precaver os seus filhos de adquirirem maus hábitos e para lhe dar bons hábitos; deve prever para eles um ensino e uma preparação oportunos; deve dar um trabalho apropriado aos adultos, dirigindo a sociedade; deve darlhes condições que os mantenham afastados das tentações inúteis, e unam estreitamente os seus interesses e deveres (OWEN, 1820 apud BENEVOLO, 1994, p. 54).
}

Percebe-se a intenção de disciplinar o comportamento dos indivíduos através de uma classificação dos seus hábitos, como bons ou ruins. Desta forma, não apenas as atividades de trabalho são determinadas, mas também as atividades do "tempo livre". A preocupação recai sobre a utilidade dos indivíduos, que devem voltar-se aos interesses e deveres reconhecidos como superiores dentro daquela comunidade.

A disciplina do tempo dos funcionários também é um assunto abordado por 
Thompson (1998). O autor relaciona a noção de tempo com as atividades cotidianas e identifica a substituição do ritmo natural das funções pelo tempo regrado pelos horários de trabalho na fábrica. Por exemplo, um artesão que produzia um sapato de acordo com a disponibilidade de matéria-prima, ou com sua vontade, intercalava horas de trabalho intenso com horas de ócio, ou seja, o trabalho estava presente na vida do trabalhador. Com o aumento do número de fábricas, este artesão não estava mais apto a concorrer com o sistema de larga escala, tendo que vender seus serviços. Sendo assim, Thompson aponta a separação entre horas para trabalho e horas para viver, e o tempo passa a servir como moeda de troca.

Marx e Engels também fazem críticas às propostas apresentadas pelos socialistas utópicos. Para eles, apesar dos autores desta corrente perceberem as más condições da classe trabalhadora e se empenharem para melhorar tal situação, concentraram-se na melhoria das condições materiais da sociedade como um todo, mas não apresentam críticas políticas sobre o sistema. Ainda, de acordo com Marx e Engels, o contexto fantasioso das situações propostas, que ignoravam as crescentes lutas entre as classes, invalidaram os valores práticos das soluções de seus projetos - que se limitaram a experimentos, muitas vezes sem sucesso, patrocinados por filantropos burgueses.

Benevolo (1994) aponta no contexto das críticas de Marx e Engels o distanciamento entre experiências urbanísticas e a política europeia da esquerda destacando a aproximação da primeira ao novo conservadorismo europeu. Segundo o autor, com a revolta operária de 1848 começaram a surgir pressões sociais e entende-se a importância de algumas reformas para a preservação das instituições de interesse. Sendo assim, percebe-se a adoção das ideias socialistas utópicas por parte daqueles que querem manter o sistema existente, bem como o controle sobre a vida do trabalhador operário.

\section{O ESTUDO DE CASO: O COMPLEXO RHEINGANTZ}

A Fábrica Rheingantz foi fundada em 1873, no município de Rio Grande, pelo comerciante brasileiro Carlos Rheingantz em sociedade com seu sogro Miguel Tito de Sá e o empresário alemão Herman Vater. O processo de industrialização da cidade foi impulsionado por dois fatores principais: o avanço econômico gerado pela atividade das charqueadas - na qual Pelotas era responsável pela produção e Rio Grande pela exportação do produto -, o que permitiu investimentos no setor industrial da cidade; e a 
localização próxima ao mar, que favorecia o escoamento de produtos (MARTINS, 2006). Sendo assim, a cidade tornou-se um local estratégico para investimentos neste setor.

A fábrica iniciou sua produção de lã em pequena escala (em 1874), tornando-se pioneira no processo de industrialização tanto da cidade (MARTINS, 2006) quanto do Estado do Rio Grande do Sul (PAULITSCH, 2003). Com a dissociação dos proprietários, passou a se chamar Fábrica Nacional de Tecidos de Lã de Rheingantz \& Cia., administrada exclusivamente por Carlos Rheingantz, que mais tarde, mudou o nome da fábrica para Companhia União Fabril. A empresa tornou-se referência na área e recebeu prêmios em exposições industriais no Brasil e no exterior. O proprietário recebeu o título de comendador, concedido por decreto imperial, como forma de reconhecimento por suas iniciativas (MARTINS, 2006; BOBADILHO e FERREIRA, 2012).

Inicialmente, a companhia localizava-se no quarteirão formado pelas ruas Conde de Porto Alegre e Almirante Barroso. Entretanto, fatores como o aumento da produção, a expansão urbana da cidade, a construção do Porto Novo e a inauguração do trecho ferroviário Rio Grande-Pelotas-Bagé, foram determinantes para a nova implantação da fábrica, em 1884, na zona leste de Rio Grande, denominada "Cidade Nova" (PAULITSCH, 2008).

Em decorrência disso, surgiram novas necessidades. A falta de transporte público do centro da cidade para o novo sítio da fábrica foi motivo de reivindicação por parte dos operários, uma vez que estes já possuíam uma jornada de trabalho de 10 horas diárias e agora precisariam percorrer um trajeto maior de locomoção.

A necessidade de assistência para manter os funcionários, atendendo as demandas de trabalho, já era percebida pela empresa: em 1884 os relatórios apontavam que a diretoria já demonstrava interesse por políticas assistencialistas (FAGUNDES apud GUIGOU-NORRO, 1995). No mesmo ano em que foram inauguradas as novas instalações, começaram as construções de habitações de baixo custo no terreno ao lado da fábrica, tendo como finalidade proporcionar moradias nas proximidades, as quais também seriam mais uma fonte de renda para a diretoria. Percebe-se que a vida do trabalhador em Rio Grande também passava a se organizar de acordo com as demandas e necessidades geradas pelo seu emprego e empregador. 


\section{Complexo Rheingantz: Implantação e Tipologia}

Concluído em 1884, o novo edifício da fábrica era composto por pavilhões, nos quais ocorriam as atividades de produção. Em seguida, somou-se a este uma edificação destinada aos escritórios e atividades administrativas. De acordo com Paulitsch (2003), não há plantas originais do prédio do escritório. Todavia, a autora trabalha com a hipótese de a edificação ter sido construída e finalizada aproximadamente entre os anos de 1909 e 1911, portanto, em um período posterior ao dos pavilhões. Vale ressaltar ainda que, segundo Paulitsch, o edifício possui sofisticação diferenciada em relação às construções da época - com modenatura formada por base, corpo e coroamento a edificação é comparada aos prédios do Maneirismo Internacional.

Diferentemente da fachada principal que, como um todo, é assimétrica, o volume da edificação dos escritórios apresenta simetria (Figura 2). Baldoni (2000) entende o edifício principal como um eixo orientador para o restante da fachada e também destaca a imponente simetria da edificação bem como a presença de mansardas e cobertura em ardósia. Outro elemento com bastante significado e que será discutido adiante neste artigo é a presença do relógio disposto no eixo de simetria da edificação principal, local de bastante visibilidade (Figura 3).

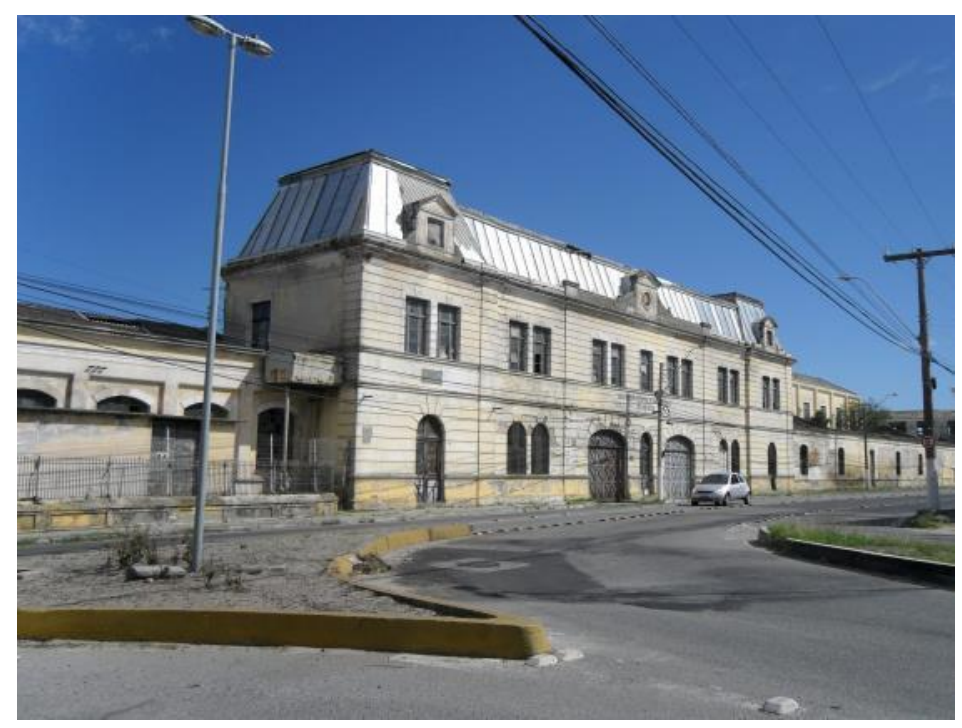

Figura 2: Fachada Principal da Companhia União Fabril. No centro, o Edifício do Escritório Fonte: Acervo das autoras, 2017. 


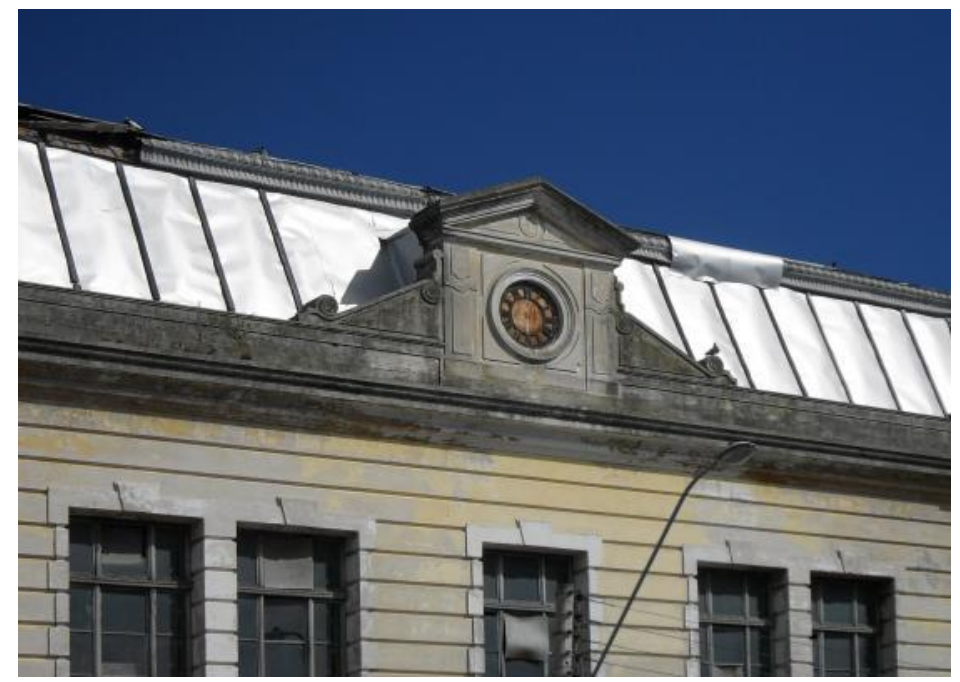

Figura 3: Detalhe do relógio disposto no centro da Fachada Principal. Fonte: Acervo das autoras, 2017.

A implantação do Complexo Rheingantz (Figura 4) aconteceu de forma gradativa tendo como marco inicial, no ano de 1885, as Casas da Fábrica. Foram construídas inicialmente 22 casas em fita ao longo da Avenida Rheingantz. Contudo, vale ressaltar que enquanto 18 residências seguem o alinhamento predial, outras quatro estão recuadas em relação ao mesmo (Figura 5). Guigou-Norro (1995) destaca essa diferença como um indício de que foram construídas em períodos diferentes, sendo as edificações recuadas posteriores àquelas implantadas no alinhamento predial. Essa suposição pode ser confirmada na vista aérea do conjunto (Figura 4), onde todas as edificações estão no alinhamento predial.

A tipologia utilizada nas edificações foi de porta e janela e de corredor lateral. $\mathrm{O}$ conjunto possui base, corpo e coroamento na fachada principal. Nas edificações mais íntegras do conjunto pode-se identificar a porta principal de duas folhas com bandeira fixa e as janelas de guilhotina. As coberturas, de duas águas, ficam encobertas pela platibanda, que apresenta ornamentos nas edificações recuadas. O jardim frontal dessas edificações possui o mesmo gradil que foi empregado nas casas dos mestres.

Posteriormente, em 1887, com tipologia de porta e janela foram construídas 39 unidades habitacionais no terreno adjacente, formando o grupo que foi denominado de “Casas do Corredor” (Figura 6) (PAULITSCH, 2003). 


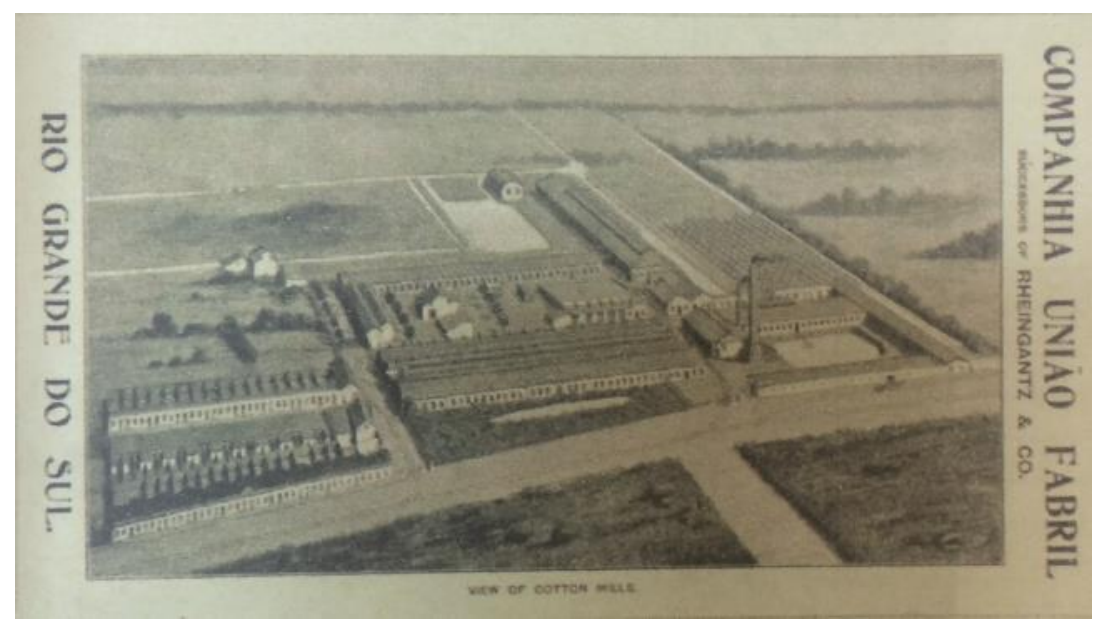

Figura 4: Instalações do Complexo Rheingantz no final do século XIX. Fonte: Acervo de Marcelo Degani apud SILVA, Rogério Piva. Quanto vale um patrimônio cultural? O oda Fábrica Rheingantz na cidade do Rio Grande - RS. Rio Grande: Editora da FURG, 2013. p.49.

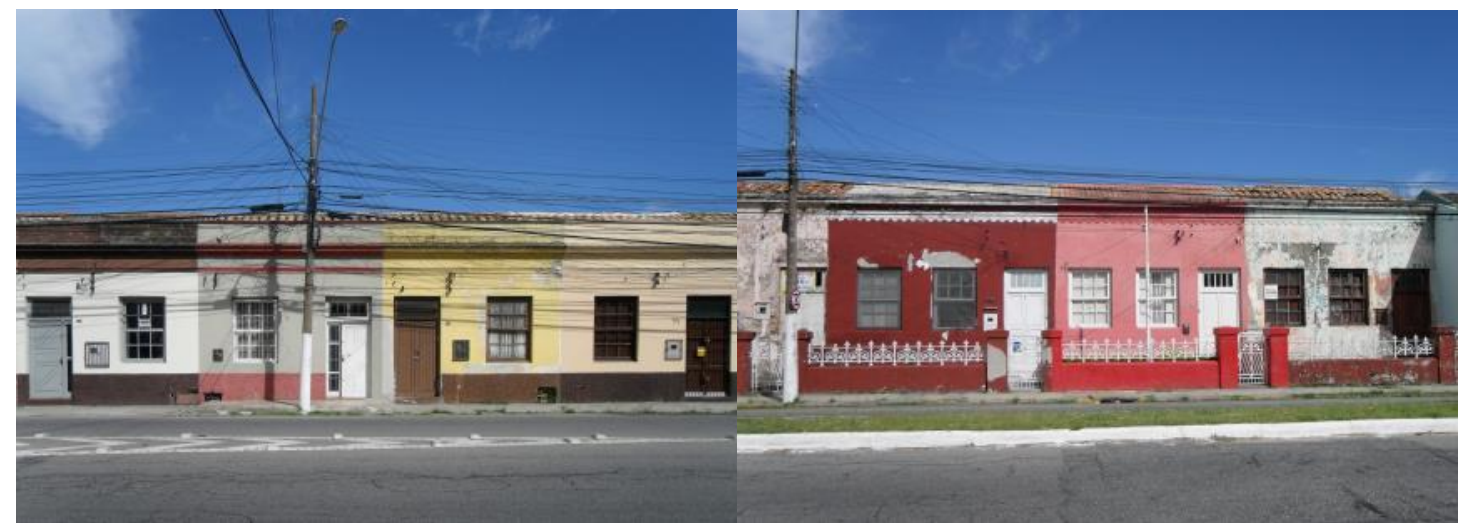

Figura 5: $\mathrm{Na}$ imagem à esquerda, 1: As Casas da Fábrica ao longo da Avenida Rheingantz, no alinhamento predial. Fonte: Acervo das autoras, 2016. Na imagem à direita, 2: As Casas da Fábrica ao longo da Avenida Rheingantz, com recuo frontal. Fonte: Acervo das autoras, 2016.

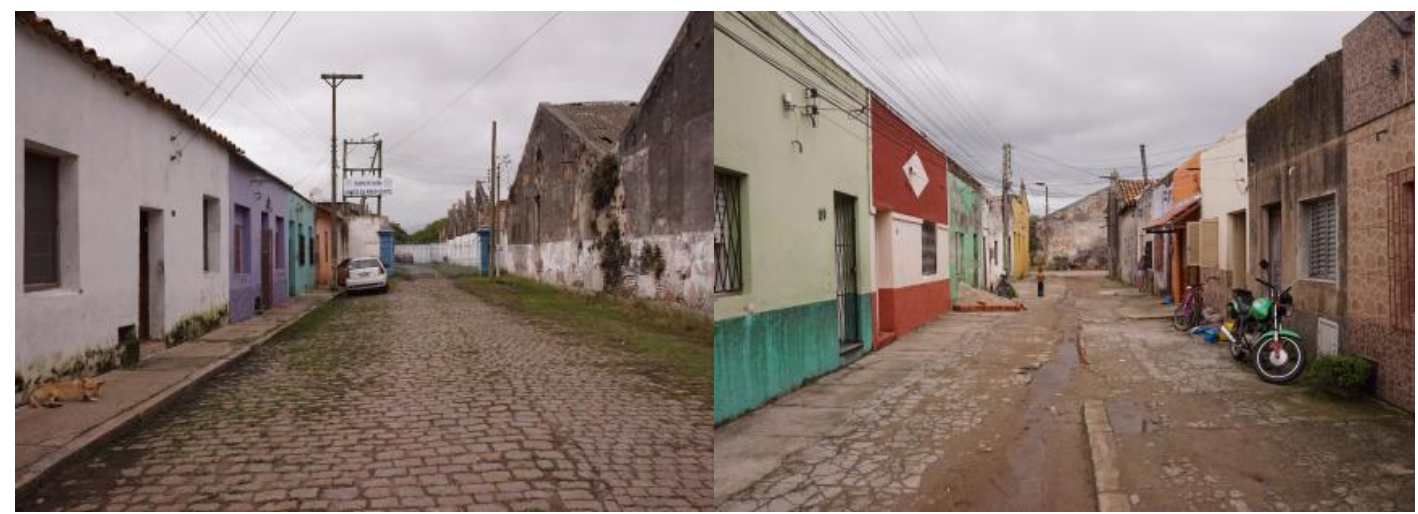

Figura 6: Na imagem à esquerda, 1: Casas do Corredor voltadas para a lateral da fábrica. Fonte: Acervo das autoras, 2016. Na imagem à direita, 2: Casas do Corredor situadas na rua paralela à Avenida Rheingantz. Fonte: Acervo das autoras, 2017. 
Os anos que sucederam a construção das Casas da Fábrica contribuíram para a expansão do complexo fabril. Segundo o relatório de 1891, a empresa adquiriu o terreno no lado oposto da Avenida Rheingantz, através de uma permuta com a municipalidade, onde foram posteriormente construídos os demais equipamentos urbanos bem como as Casas dos Mestres (PAULITSCH, 2008). De acordo com Guigo-Norro (1995), das seis habitações destinadas aos mestres, quatro eram isoladas - casas de números 156 e 130 (Figura 7), 102 e 46 (Figura 8) - enquanto as outras duas eram reunidas em um único volume - casas de números 4 e 5 (Figura 9). Ainda, devido às suas similaridades arquitetônicas, um grupo de seis casas para operários (Figura 10) foi integrado ao contexto das Casas dos Mestres.

As residências atribuídas aos mestres (possuidores de um saber que os qualificava como mão de obra especializada) possuem uma linguagem arquitetônica diferente das casas destinadas aos operários, uma vez que em sua maioria são casas isoladas no lote, todas possuindo recuo frontal e plantas amplas, com elementos e detalhes arquitetônicos diferenciados, os quais fizeram com que cada uma delas fosse reconhecida como elemento singular (GUIGO-NORRO, 1995).

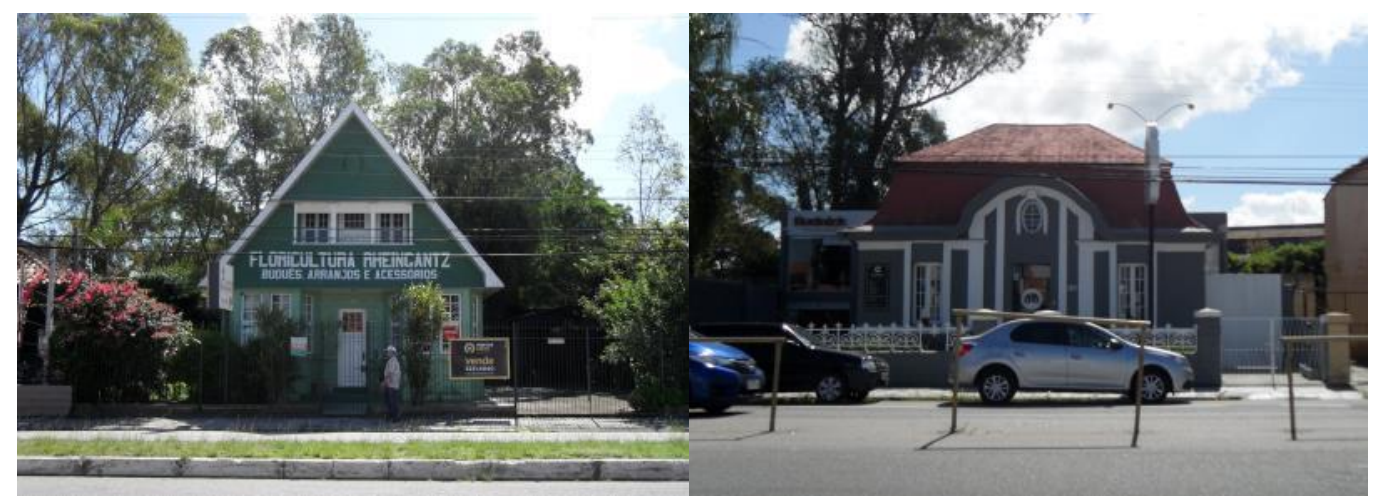

Figura 7: Na imagem à esquerda, 1: Casa de Mestre número 156. Fonte: Acervo das autoras, 2016. Na imagem à direita, 2: Casa de Mestre número 130. Fonte: Acervo das autoras, 2016. 


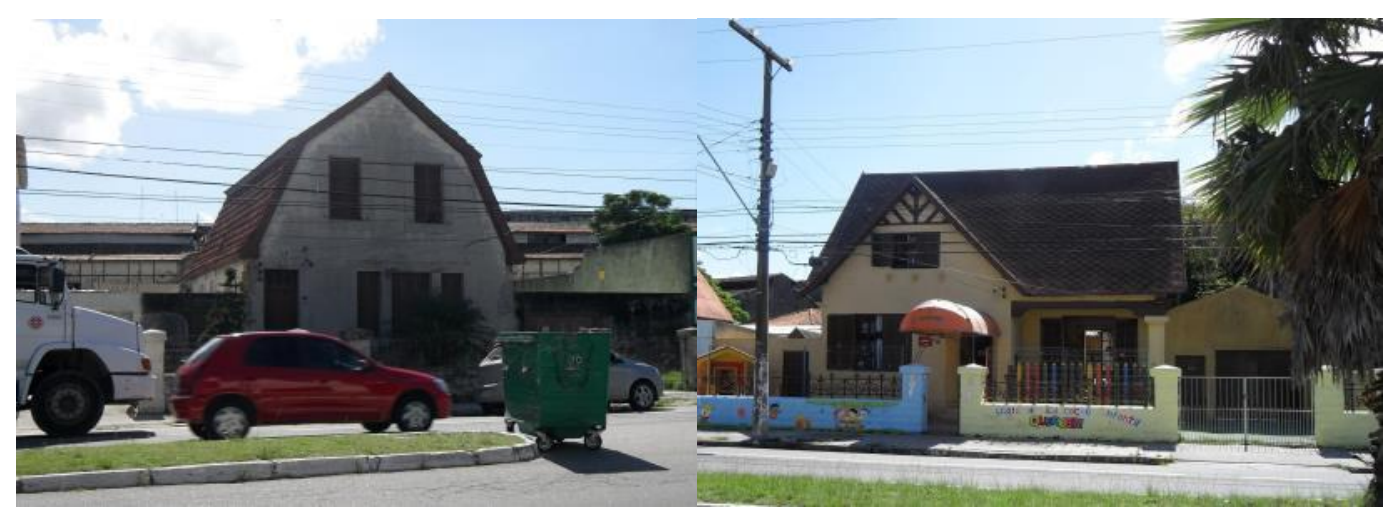

Figura 8: Na imagem à esquerda, 1: Casa de Mestre número 102. Fonte: Acervo das autoras, 2016. Na imagem à direita, 2: Casa de Mestre número 46. Fonte: Acervo das autoras, 2016.

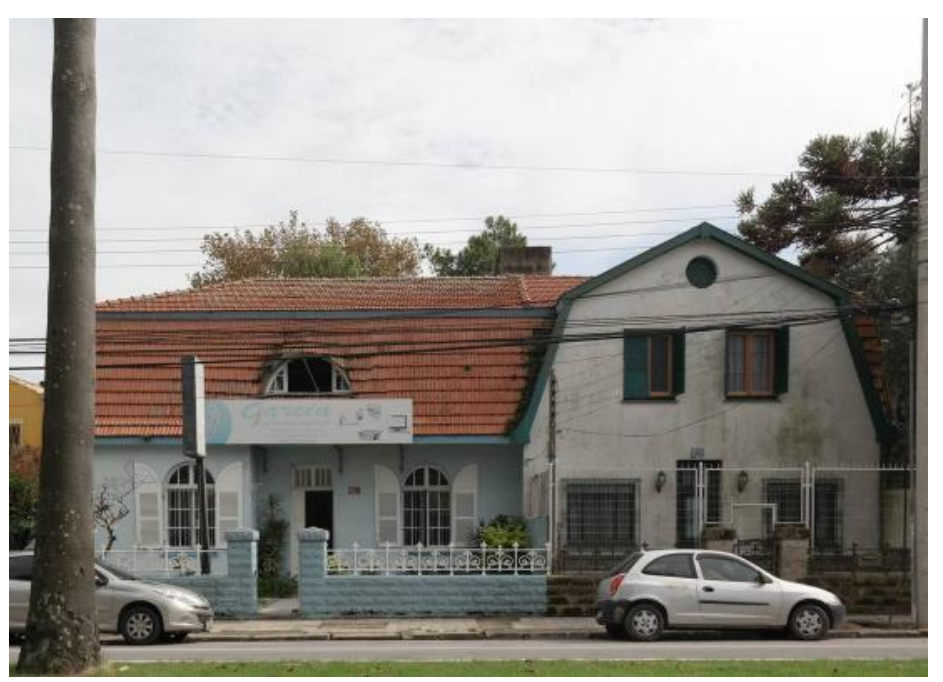

Figura 9: Casas de Mestre números 4 e 5. Fonte: Acervo de Marina Mecabô, 2016.

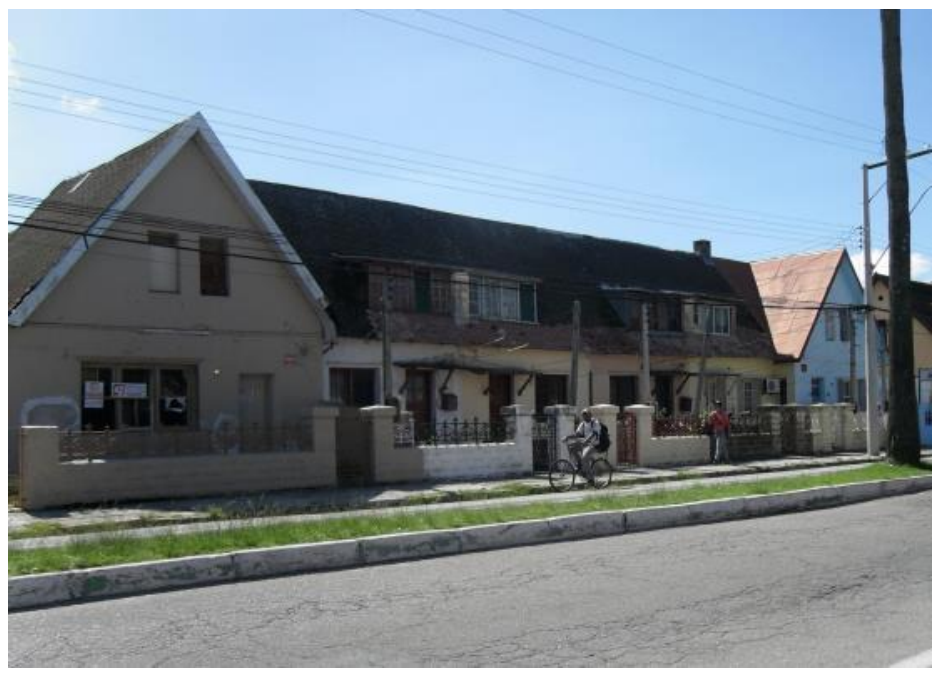

Figura 10: Grupo de 6 casas para operários em 2016. Fonte: Acervo das autoras. 
O projeto do Complexo Rheingantz não comportou apenas casas para seus funcionários. Foram projetados e construídos cinco equipamentos urbanos que integram o conjunto: Armazém Cooperativo, Ambulatório Médico, Grupo Escolar Comendador Rheingantz, Jardim de Infância e o Cassino dos Mestres. O Ambulatório Médico (Figura 11) e o Armazém Cooperativo (Figura 12) foram os primeiros equipamentos urbanos construídos, sendo datados, respectivamente, de 1886 e 1891. Estes situam-se no terreno adjacente à fábrica marcando as duas esquinas de entrada para as casas do corredor. As edificações têm os mesmos moldes construtivos das Casas da Fábrica, contudo possuem plantas mais amplas, com melhores acabamentos e suas fachadas são dotadas de ornamentação (PAULITSCH, 2003).

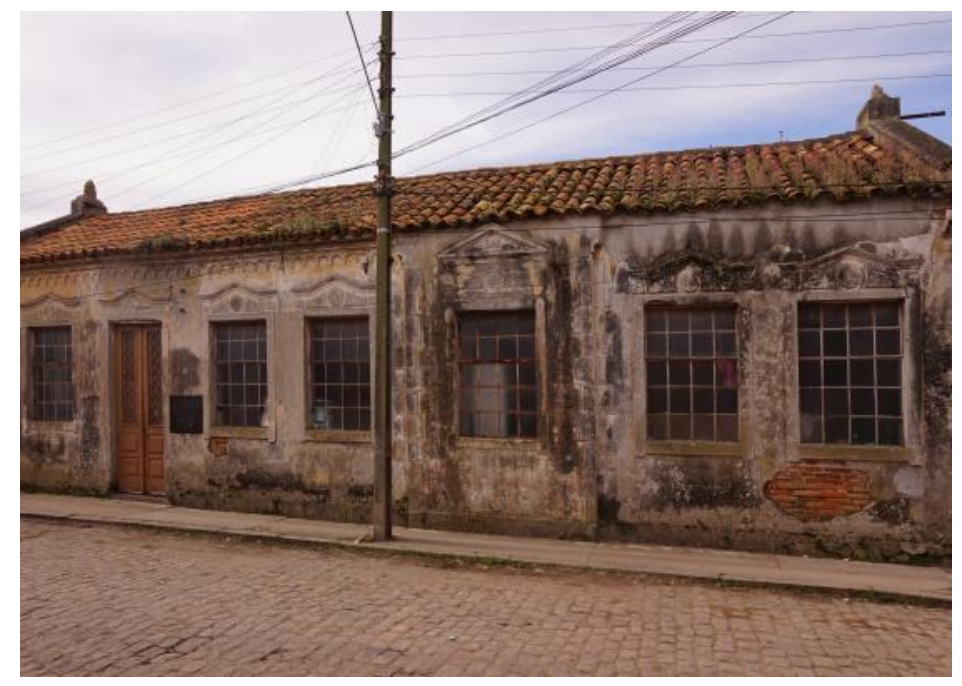

Figura 11: Ambulatório Médico. Fonte: Acervo das autoras, 2016.

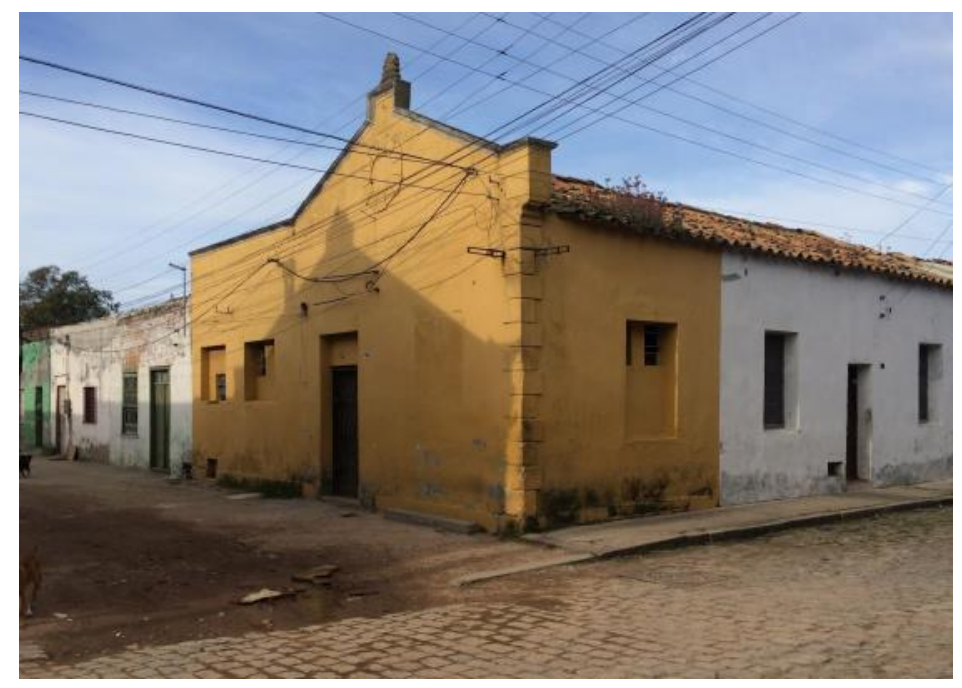

Figura 12: Armazém Cooperativo. Fonte: Acervo das autoras, 2016. 
Em 1911 a companhia fabril contratou o Escritório de Engenharia de Rodolfo Ahrons para a elaboração e execução dos demais equipamentos urbanos. O Cassino dos Mestres (Figura 13) foi projetado com o objetivo de atender as necessidades de habitação e lazer dos mestres da fábrica, localizado na Avenida Rheingantz, $n^{\circ}$ 194, destacando-se pela sua forma e linguagem arquitetônica (GUIGOU-NORRO, 1995). Sua localização é evidenciada, pelo fato de estar implantado na esquina da Avenida Rheingantz com a Rua 2 de Novembro, agindo, assim, como um ponto focal e marco visual na região. $\mathrm{O}$ programa espacial original caracterizava-se por duas entradas: a principal, pela Avenida Rheingantz e a de serviços, pela fachada lateral direita do prédio. Este possuía, no andar térreo, quatro salas de uso social, um banheiro, uma cozinha e uma área de serviço, já o segundo pavimento foi destinado aos dormitórios (PAULITSCH, 2007).

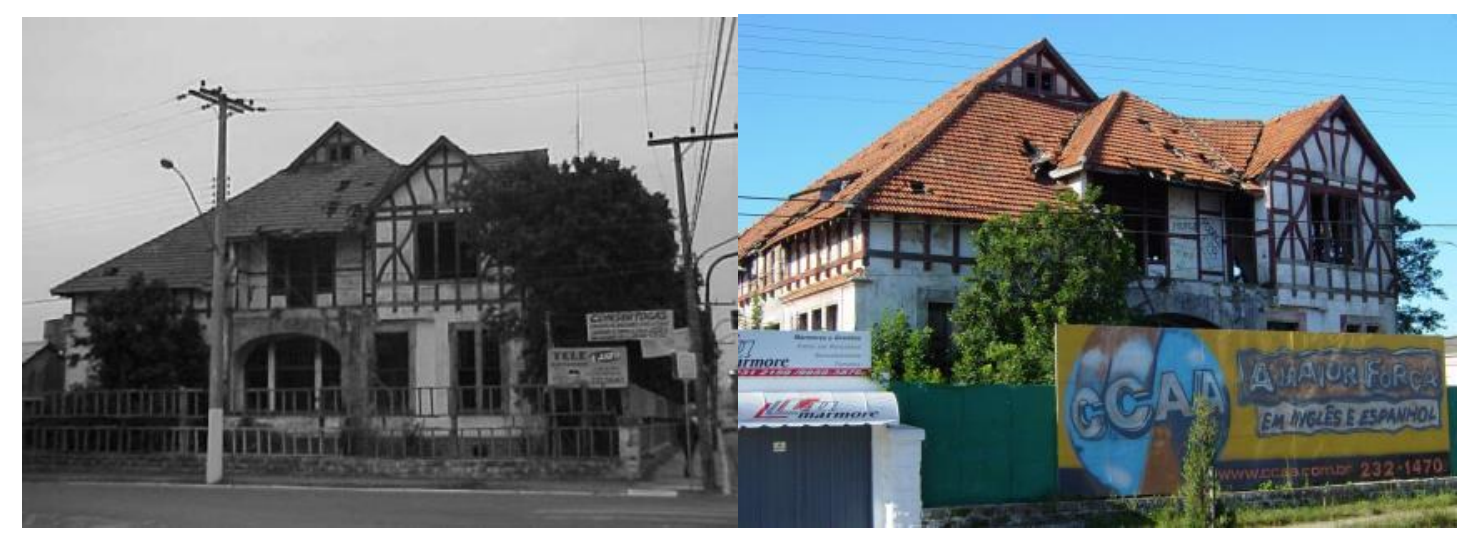

Figura 13: Na imagem à esquerda, 1: O Cassino dos Mestres. Fonte: Acervo de Oscar Décio Carneiro. Na imagem à direita, 2: Situação do Cassino dos Mestres em 2016. Fonte: Acervo das autoras.

No terreno adjacente ao Cassino dos Mestres foi construído, no mesmo ano, o Grupo Escolar Comendador Rheingantz (Figura 14). Esta construção possui o estilo arquitetônico maneirista e dispõe de uma singularidade, se comparada com as edificações do entorno, a implantação em forma de $\mathrm{C}$ com um volume de cobertura único com mesmo formato (PAULITSCH, 2007). O propósito dessa edificação era de comportar o programa educativo, que consistia em aulas de ensino básico e treinamentos, ministradas aos domingos. Segundo Guigou-Norro (1995) esse estabelecimento atendia exclusivamente aos filhos dos operários que trabalhavam na empresa, os quais revezavam as aulas conforme as atividades exercidas na fábrica. 


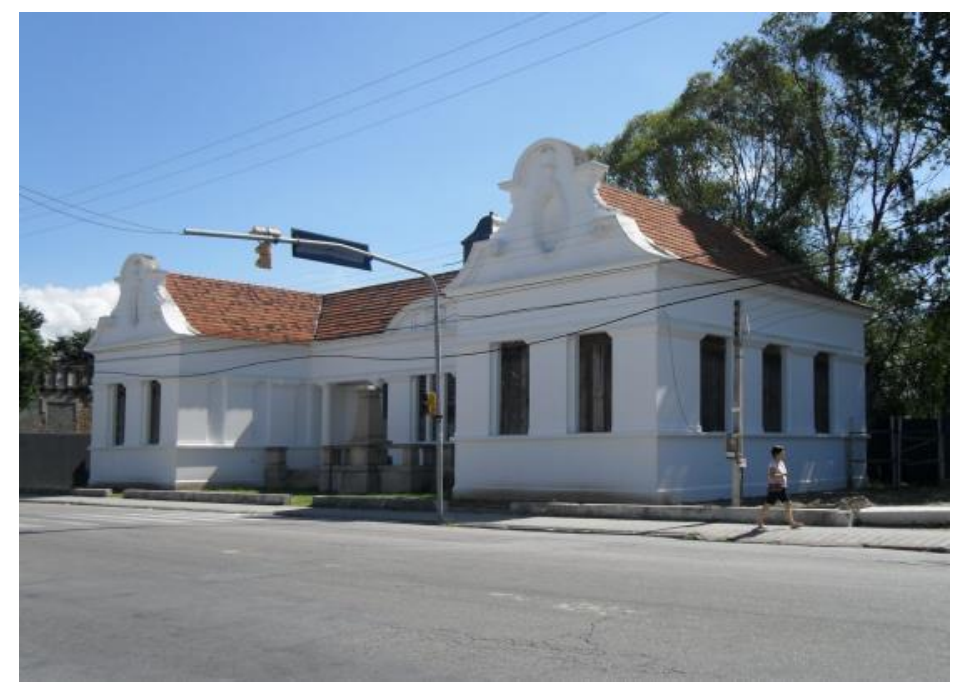

Figura 14: Grupo Escolar Comendador Rheingantz. Fonte: Acervo das autoras.

O último equipamento urbano projetado pelo Escritório de Engenharia de Rodolfo Ahrons foi o Jardim de Infância (Figura 15). Localizado na Avenida Rheingantz, acompanha o recuo predial de quatro metros, preestabelecido pelo Cassino dos Mestres. A partir da observação destas duas edificações, nota-se a afinidade arquitetônica que elas possuem entre si, devido aos detalhes e elementos da composição de suas fachadas se apoiarem no mesmo repertório. O propósito para a construção desta edificação foi de servir como creche para os filhos dos funcionários da fábrica. Sua planta original era composta por duas salas e uma área de serviço no térreo e três quartos e uma cozinha no segundo pavimento.

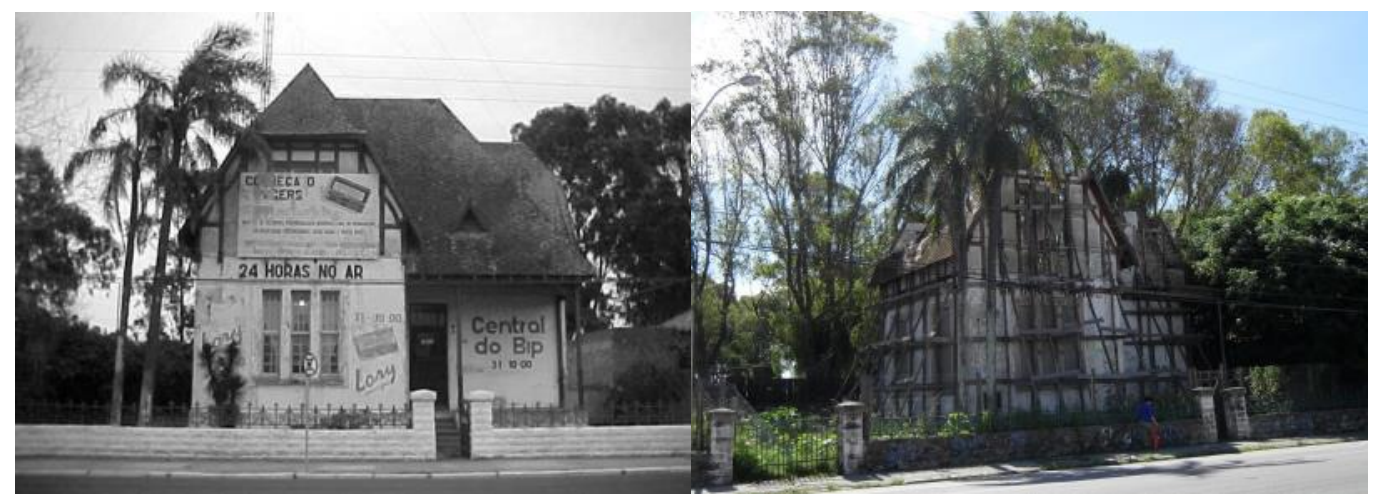

Figura 15: Na imagem à esquerda, 1: Jardim de Infância. Fonte: Acervo de Oscar Décio Carneiro. Na imagem à direita, 2: O Jardim de Infância em 2016, bastante deteriorado. Fonte: Acervo das autoras 


\section{A Expansão da Fábrica, a Cidade Nova e a Nova Vida na Cidade}

A implantação do Complexo Rheingantz redesenhou a vida na cidade. A estrutura física da Fábrica somada a uma proposta pautada pela assistência aos trabalhadores, com vistas ao atendimento das necessidades de produção, atuou como um mecanismo de controle e paternalismo social.

A expansão da Fábrica Rheingantz para a "Cidade Nova" não só movimentou a economia da cidade de Rio Grande, como também modificou a morfologia urbana. Paulitsch comenta que a Avenida Rheingantz, modelada a partir desta ótica, reproduz um exemplo da influência germânica na arquitetura do sul do país (PAULITSCH, 2008 apud COPSTEIN, 1975). Nota-se que o sistema de implantação da Vila Operária foi concebido a partir de uma categorização funcional, onde os moradores foram alocados de acordo com as funções que exerciam na fábrica, tendo como uma barreira visual a própria Avenida.

Isto dificultou a comunicação de membros de diferentes classes e, ao mesmo tempo, facilitou a comunicação entre pessoas de uma mesma categoria funcional, uma vez que as Casas dos Mestres eram destinadas para os funcionários graduados, muitas vezes imigrantes europeus. A Vila Operária e as Casas da Fábrica, por sua vez, eram atribuídas aos seus subordinados.

Segundo Guigou-Norro (1995) a comunicação também podia ser dificultada ou favorecida pelo grau de permeabilidade existente entre a articulação dos espaços públicos e privados. Analisa-se que o fato da implantação das casas dos operários terem sido feitas uma adjacente a outra e no alinhamento predial impôs uma maior proximidade das pessoas dessa classe, em razão de muitas vezes o espaço público ter sido uma extensão do espaço privado. Por outro lado, as Casas dos Mestres foram construídas soltas no lote, estabelecendo uma distância física entre as edificações e uma relação indireta com o espaço público através do jardim frontal.

Pode-se considerar que a Vila Operária foi uma extensão das relações do processo de trabalho capitalista que a fábrica exercia, uma vez que suas propostas assistencialistas tinham como finalidade principal a geração de lucro para a própria empresa. Isto fica evidente por meio da análise das técnicas adotadas para a distribuição e construção das casas para os funcionários. Como mencionado anteriormente, o tipo de habitação era diferenciado para os operários e os funcionários graduados. Essas diferenças têm efeitos para além da tipologia arquitetônica, uma vez que era cobrado um valor de aluguel para 
cada tipologia e localização da casa, sendo este assegurado pelo salário recebido pelo funcionário. As Casas do Corredor eram as mais baratas, sendo assim quem as ocupava eram os operários com os menores salários, mantendo e consolidando a estrutura hierárquica. A partir desta análise é possível estabelecer uma relação entre a variante tipológica das edificações e a sua localização com a categoria funcional dos operários.

Outro ponto que pode ser analisado é a expressão material do conceito de poder disciplinar. Segundo Foucault é preciso "ligar a distribuição dos corpos, a arrumação espacial do aparelho de produção e as diversas formas de atividade na distribuição dos postos" (FOUCAULT, 1992 apud GUIGO-NORRO, 1995, p. 133) para que se mantenha disciplina no viver. Esse aspecto foi traduzido através da organização e distribuição funcional, no interior da fábrica, disciplinando seus funcionários através da racionalização do processo de produção. Por outro lado, a localização das moradias e suas dimensões contribuíram para a construção dos sentidos culturais de identidade e de hierarquia, a exemplo a premiação da dedicação e do desempenho do trabalhador através de uma ascensão nos tipos de moradia (GUIGO-NORRO, 1995).

\begin{abstract}
Através desses procedimentos, o poder disciplinar organizou o espaço de modo a vigiar o comportamento de cada um dos indivíduos (operários) e permitir medir suas qualidades ou méritos. Na medida em que um operário escalava posições na hierarquia da empresa, era premiado pela troca de sua casa por uma outra melhor qualificada. Quem morava no corredor interno ocupava posições de menor destaque no quadro funcional e os que habitavam as casas da avenida Rheingantz tinham maior qualificação (GUIGONORRO, 1995, p. 168).
\end{abstract}

Além de disponibilizar habitações para operários nas vizinhanças da fábrica, as práticas de lazer e assistência social também limitavam as opções de vivência cotidiana dos funcionários, acentuando o processo de dominação e disciplinarização. Correia e Gunn (1996), a partir da análise dos estudos de caso das indústrias Paulista em Pernambuco e Rio Tinto na Paraíba, abordam esta temática da influência da indústria sobre as atividades urbanas ocorridas dentro dos complexos fabris. Segundo os autores, as indústrias mantinham a ordem a partir da "formação e reprodução de operários regrados e produtivos" (CORREIA e GUNN, 1996, p. 5). Portanto, sendo a fábrica proprietária dos espaços e equipamentos urbanos, estes passam a servir como instrumentos de controle social. Ou seja, através das possibilidades existentes no local, como lazer, habitação, escola, enfermaria e armazém, o operário está destinado a usufruir 
aquilo que lhe é oferecido, quando estiver disponível. Nesta perspectiva, Correia e Gunn (1996) também destacam a questão do controle do consumo e tempo dos operários.

A empresa passa a influenciar a rotina dos trabalhadores desde a escolha dos alimentos que estes irão consumir, ditada de acordo com os produtos disponíveis no armazém, até as suas possibilidades de lazer, determinando quando deveriam ir para casa descansar para repor a energia para o trabalho (CORREIA e GUNN, 1996).

Sendo assim, a interferência dos interesses fabris se demonstram presentes nos diversos âmbitos do cotidiano do trabalhador. O ambulatório também se faz conveniente para assegurar que os funcionários estejam saudáveis e aptos para o trabalho.

Nessa mesma perspectiva insere-se a construção do jardim de infância, datado de 1911, uma vez que, após sua construção, as mulheres que trabalhavam na fábrica possuíam um lugar para deixar os filhos enquanto exerciam suas 10 horas diárias de trabalho. Ou seja, uma vez que grande parte das necessidades da vida do trabalhador está entrelaçada com os serviços da fábrica, este passa a estar submetido ao controle e vigilância da mesma. Isto evita a possibilidade de o trabalhador se rebelar, visto que não é apenas a sua vida que depende da fábrica, mas também a vida de toda a sua família.

Outro exemplo que pode ser mencionado é a Escola Comendador Rheingantz, situada no lado oposto às Casas da Fábrica na Avenida Rheingantz, na qual os filhos dos funcionários eram matriculados. Visava-se, a partir dela, uma maior autonomia para o complexo a partir do atendimento das necessidades do trabalhador, criadas a partir dos interesses da fábrica. Se por um lado os filhos dos trabalhadores tinham acesso a uma alfabetização básica, por outro eram ministradas oficinas para que estes pudessem exercer atividades de acordo com os interesses administrativos da empresa, disciplinando os futuros operários. Correia e Gunn (1996) também destacam a escola como importante mecanismo de controle social. Os mesmos apontam, além da capacitação para o trabalho, a disciplina para a aceitação da hierarquia existente e a introdução ao regime temporal estabelecido pelo sistema fabril.

Bem como o calendário, que possui a função de dar ritmo e sincronizar as atividades coletivas (DURKHEIM, 1989 apud MACHADO, 2012), neste contexto, o relógio também possui esta função. Segundo Thompson (1998), com o aumento da complexidade no sistema de produção fabril, a sincronização do tempo dos trabalhadores foi necessária, e desde o século XIV já havia relógios em certos pontos das fábricas e dos espaços públicos para orientar as populações urbanas. Ainda, segundo Sue (1995 apud MACHADO, 2012), toda a sociedade possui uma lógica de "tempo social dominante", 
ou seja, é coordenada a partir de uma prática social preponderante que acaba por influenciar ou determinar o ritmo das demais atividades. Sendo assim, a disposição do relógio em determinados espaços evidencia a atividade que determina o ritmo de uma sociedade. Neste caso, o trabalho fabril exerce este domínio.

A fábrica estrutura o tempo, por ditar padrões e ocasiões de consumo, conteúdo e formato do espaço escolar e, mesmo, determinando feriados e datas festivas. Assim, colabora para dar sentido aos intervalos de tempo, estruturando, portanto, os períodos que organizam o cotidiano (LEACH, 1974 apud MACHADO, 2012). Machado (2012) também chama a atenção para o tempo como eixo de ligação entre um indivíduo e a sociedade a qual este pertence. Em suas palavras, "o tempo cria base para a atribuição de significados que vão ordenar a vida e as expectativas quanto ao futuro - imprimindo, marcando, oprimindo e conformando o indivíduo" (p. 14).

Neste sentido, verifica-se que o sistema gerado pela construção do sítio fabril atuou como dominador da vida do trabalhador. Conforme já mencionado, a estrutura arquitetônica do espaço - as tipologias, implantações e equipamentos - exerce influência não apenas no âmbito profissional, mas também nas relações pessoais dos trabalhadores. Bem como no caso exemplificado por Calabi (2012) neste artigo, a presença do relógio no centro da fachada principal da Fábrica Rheingantz não possui uma conotação apenas estética, mas também têm significado: naquele local, e para as pessoas que lá residem, o tempo e o ritmo da vida refletem o tempo e o ritmo de produção da fábrica.

\section{CONCLUSÃO}

Partindo da análise de correntes progressistas do final do século XIX, foi possível estabelecer um diálogo entre estas posturas e as ideias que influenciaram a implantação do novo sítio fabril da empresa Rheingantz. Neste sentido, buscou-se entender a perspectiva de diferentes teóricos sobre a organização social e a estrutura arquitetônica da época da Revolução Industrial, com o intuito de referenciar o estudo de caso da fábrica. Além da contextualização histórica da inserção e consolidação do espaço de trabalho, buscou-se compreender os elementos arquitetônicos componentes deste, bem como o seu significado na vida cotidiana dos trabalhadores.

A compreensão do período histórico no qual as ideias progressistas tiveram início, bem como as diferentes teorizações a respeito da realidade inaugurada por uma sociedade 
fabril, foi fundamental. A nova forma de trabalhar e de se relacionar com o trabalho foram decisivas para uma nova configuração da vida social. Neste sentido, as teorias não estão isoladas dentro da questão arquitetônica, mas sim abrangem o entendimento da sociedade como um todo, inclusive no que diz respeito às suas relações mais complexas e abstratas, como a percepção do tempo.

A literatura abordou de forma ampla a relação entre a fábrica e a vida social, assumindo estas como detentoras do domínio do tempo. Não apenas o tempo e as atividades de trabalho são administrados pelo dono da fábrica, cujas escolhas perpassam pela vida familiar, pelo lazer, pela escolarização e pelo padrão de consumo dos funcionários. Neste sentido, pode-se dizer que esta foi a função assumida pela Rheingantz no município de Rio Grande. A partir da análise das residências e equipamentos urbanos que constituíram o sítio fabril, foi possível identificar a extensão das relações existentes dentro da fábrica, na qual os elementos arquitetônicos serviram para reforçar as relações existentes no local de trabalho e, ainda, repercutiram no comportamento de seus funcionários fora deste.

Assim como nos projetos de alguns teóricos progressistas - a exemplo da Comunidade cooperativa de Owen, do Phalastére de Fourier e do Familistério de Godin - a utopia de organização social por meio de comunidades isoladas em torno de um objetivo, neste caso o objetivo econômico, se demonstrou paternalista e controladora das diversas dimensões da vida dos trabalhadores. Entender as correntes progressistas no início da Revolução Industrial possibilita entender a dimensão do significado dado às edificações dos sítios fabris. A complexidade e a transformação das ideias do início da revolução até a implantação dos sítios fabris no século XX demonstraram-se essenciais para entender a importância do Complexo da Fábrica Rheingantz. A configuração arquitetônica revelou muitos aspectos sobre o espaço edificado, quando se buscou, a partir dela, a compreensão de suas funções e significados.

O reconhecimento e tombamento do Complexo Rheingantz em 2013 pelo IPHAE (Instituto do Patrimônio Histórico e Artístico do Estado do Rio Grande do Sul) demonstra sua importância histórica e social. O estudo do mesmo pode ser justificado por meio da relação que o espaço e a sua organização estabelecem com as ideias sociais e a vida em sociedade. Reflexões como esta são necessárias para que análises e compreensões sobre a paisagem urbana ultrapassem o caráter unicamente estético, visto que questões econômicas, políticas e culturais perpassam as decisões projetuais e se revelam na arquitetura da cidade. 


\section{REFERÊNCIAS}

BALDONI, Vanessa Schmidt. Requalificação, Revitalização, Reciclagem do Complexo Rheingantz. 2000. (Trabalho de Graduação) Faculdade de Arquitetura e Urbanismo, Universidade Federal de Pelotas.

BENEVOLO, Leonardo. As Origens da Urbanística Moderna. Lisboa: Presença, 1994. BOBADILHO, S. S.; FERREIRA, M.L.M.. A História oral no estudo do patrimônio industrial na cidade do Rio Grande-RS. In: VI Colóquio Latino Americano sobre Recuperação e Preservação do Patrimônio Industrial, 2012, São Paulo. Anais do VI Colóquio Latino Americano, 2012.

CALABI, Donatella. História do urbanismo europeu: questões, instrumentos, casos exemplares. São Paulo: Perspectiva, 2012.

CHOAY, Françoise. O Urbanismo - Utopias e Realidades. São Paulo: Editora Perspectiva, 1979.

GUIGOU-NORRO, J. A. A Vila Operária na República Velha: o caso Rheingantz. 1995. (Dissertação de Mestrado). Faculdade de Arquitetura, Universidade Federal do Rio Grande do Sul.

GUIMARÃES, P. Paulino. Configuração Urbana: Evolução, Avaliação, Planejamento e Urbanização. São Paulo: Prolivros, 2004.

GUNN, Philip; CORREIA, Telma de Barros. O mundo urbano das Casas Pernambucanas - as cidades empresariais de Paulista e Rio Tinto. In: IV Seminário de História da Cidade e do Urbanismo, V. I, 1996. Anais do IV Seminário de História da Cidade e do Urbanismo. Rio de Janeiro: PROURB-FAU-UFRJ, 1996. p.390-403.

IPHAE. Complexo Rheingantz. Instituto do Patrimônio Histórico e Artístico do Estado, Porto Alegre. Bem Tombado. Online. Disponível em: <http://www.iphae.rs.gov.br/Main.php?do=BensTombadosDetalhesAc\&item=43405>. Acessado em 21 jul, 2016.

IPHAE. Histórico. Instituto do Patrimônio Histórico e Artístico do Estado, Porto Alegre. Disponível em: <http://www.iphae.rs.gov.br/Main.php?do=HistoricoAc\&item=25>. Acessado em 21 jul, 2016.

MACHADO, Jorge. Reflexões Sobre o Tempo Social. Revista Temática Kairós Gerontologia. São Paulo, v. 15: "Vulnerabilidade/Envelhecimento e Velhice: Aspectos Biopsicossociais", p.11-22, dez. 2012. Online. São Paulo: FACHS/NEPE/PEPG/PUCSP. 
MARTINS, S. F. Cidade do Rio Grande: industrialização e urbanidade (1873 - 1990). Rio Grande: FURG, 2006.

MARX, Karl; ENGELS, Friedrich. Manifesto do Partido Comunista. São Paulo: Escala, 1848.

PAULITSCH, Vivian da Silva. Rheingantz: uma vila operária em Rio Grande. 2003. (Dissertação de Mestrado). Instituto de Filosofia e Ciências Humanas, Universidade Estadual de Campinas, Campinas, 2003.

THOMPSON, Edward P. Costumes em Comum. São Paulo: Companhia das Letras, 1998. 